\title{
Covid-19 Period: Is it the Right Time to 'Open the Door' of De-Grading and De-Testing?
}

\author{
Dwi Rosita Sari ${ }^{1,2}$ \\ ${ }^{1}$ National Dong Hwa University, Taiwan ROC \\ ${ }^{2}$ Universitas PGRI Madiun, Indonesia \\ *Corresponding author. Email: $\underline{\text { dwirositasari@unipma.ac.id }}$

\begin{abstract}
World is not yet healing. Covid-19 pandemic has already altered many aspects of life, including in education field. Indonesian Ministry of Education and Culture has already set and implemented a vivid scenario towards online learning for students. Since every single aspect in education reach new adaptation, our practical scenario being very important towards teaching-learning process. De-grading and de-testing sound essential to be discussed and implemented in this period of time. This article reveals crucial ideas and implementation towards de-grading and detesting through personal reflection.
\end{abstract}

Keywords: Covid-19, De-grading, De-testing

\section{INTRODUCTION}

The spread of Covid-19 had already reached the highest point in Indonesia. This condition creates a profound effect on many aspects, appertain on educational field. As stated by Martini et al., (2019) throughout history, pandemics are known to affect human life in many ways. Indonesian Ministry of Education and Culture, forcefully, dismissing classroom interactions and activities. Practically and psychologically, the unpredictable school closure brings many impacts towards students and teachers. Some drawbacks have already found such as the limitation access of study and unequal perspective towards teaching learning process. The highlighted issues are about 'assessment and grading' towards students' study result since this pandemic almost passed 3 semesters in educational period system. As the planning, in the beginning of July 2021, Indonesian Ministry of Education Minister, Mr. Nadiem Anwar Makarim, B.A., M.B.A. has announced that they will begin a half system of classroom meetings, but the fact that the newest update of June $27^{\text {th }}, 2021$ there is more than 20.000 cases per day. Kompas.com noted that Covid-19 cases in Indonesia reaches 2.115 .304 cases. By having the worse condition, it will be no possibility for the Ministry of Education to open offline class meeting in the near period of time. The best scenario is about continuing the online class meeting towards technology provided.

Those background of newest Indonesian condition related to learning difficulties towards covid-19 offline class, it is truly in urgency that teachers should be more critical and creative towards teaching learning. Preparing some engaging methods, learning style and alternative assessments.

\subsection{De-testing and De-grading}

These two terms used as a result of criticism towards ordinary testing and grading systems in the school. Bower \& Thomas (2016) noted that in traditional grading, this is basically what we report: Student compliance. Many teachers' gradebooks are reports of activities completed when they should be reports of learning, the evidence of mastery demonstrated for each standard or outcome. Related to this statement, grading, before, understood as one think which should be done by teacher in giving clear report which is believed in the name of students', parents' and administrators' needs toward giving rank and sort the student practically.

Finding the facts that high-stakes test creates many debatable points of view and moving rapidly to the $21^{\text {st }}$ century-competence needs, many teachers then focus on innovation in educational reform called 'De-testing and De-grading'. In addition, Bower \& Thomas (2016) 
stated that even better, they demonstrate the true professional's tool: revising one's thinking in light of new perspective or evidence. De-testing and De-grading as a result of sensitivity perspective against standardized test that already set in very rigid system, but still many aspects can make these two terms being exist in educational process. Traditional grading and ordinary testing known as some ways which are killed students' uniqueness and creativity towards learning process. They will always focus on the report that is popular with 'scores'. Pressure on having high scores being very frustrated not only for students, but also for teachers, parents and administrators. Based on those complicated ideas about testing and grading, it is essentials for teachers in conducting the alternative assessments.

\section{DISCUSSION}

\subsection{De-testing and De-grading in Covid-19 Period: Is it the right time to be implemented?}

Coronavirus spreads to fast and affects all aspects, including school world. Indonesian Ministry of Education closed all schools and universities to avoid the wider spread of coronavirus and cut the coronavirus's clusters from schools. The school closure affects and brings some drawbacks for students and teachers since all the teaching learning process is in the term of 'distance learning'. Distance learning here is identified as the learning process conducted without face-to-face interaction between teacher and students in the classroom. The Minister of education set up many programs in supporting this distance learning process and forced every educational officer and party like policy makers, administrators, principals, researchers, teachers, parents and students should do their best and be ready in limited time on facing up this condition.

Re-design the curriculum, teaching strategies and teaching methods to be very urgent to do by the teacher. It is supported by Tadesse \& Muluye (2020) that the educational institutions design strategies to recover lost learning, and return students to school when schools reopen. Coronavirus has been impacting the face-to-face education system of developing countries. Moreover, inadequate technical competence, lack of qualified online tools, inexperience of instructors, students' difficulties are the major points to be highlighted in this period of coronavirus. In this situation, all members of educational officer should focus on educational reform and transform and make it being the main thing to do to close the needs of 'lost learning'. 'Lost learning' creates many limitations towards teaching learning process, one of it is remote assessment towards teaching and learning. Senel \& Senel (2020) stated that valid and reliable assessment results are crucial to be able to control whether the educational goals have been achieved or not. The coronavirus period of time is identified as the best time to start educational reform and transform towards assessment. Testing and grading in the name of assessment is understood to be 'frustrated' and 'pressure' for every single student. Badly and worried condition of coronavirus, make everything worse for students. The further question, then, is 'What is the best way to assess students in distance learning?. Herein, alternative assessment is chosen as the best answer toward that question. Before coronavirus period, the best choice is standardized test towards paper-based test in classroom.

\subsection{Alternative Assessment as Practical 'De- testing and De-grading'}

Grading, de-grading and un-grading are processes that could not be chosen by practical teacher. Grading is always be important part in teaching learning process. The score-based grading is always be a trap for teachers. This result reports are very useful for every student to grade their identity, name their grade and known their level of study. Moreover, the educational officers force teacher to make a report towards students learning progress through scores then continues to the parents. In this phase, the scores are only be technical progress reports.

In the other hand, it is very essential to define the first thing that should be understood by all students, teachers, principals, educational officers and policy makers is the answer of a question "What is the objectives on enhancing the test? What should you do then after you got the scores??". Those all parties have their own tendency towards these scores as technical reports. Bower \& Thomas (2016) raised a very important question to be thought "Is this what good teachers do: Report students' learning against society's goals assigned to this subject at this grade level? Or, is our job something more than record keeping and checking off boxes on accountability sheets? Are we supposed to identify how our students rise and fall with curriculum goals and that simple act will lead to their success, or is it something else?". Standardized test, still, believed as the most appropriate to test the academic levels of students. Grading and testing sounds to be very technical in describing the results of teaching learning process. It just supports the grading as students' identity. Furthermore, a question about how the creativity, emotional, social, and physical growth of students can be tested/scored?. Critics arise when the alteration perspective from "valuing what we measure into measuring what we value", "raising students' selfworth or raising scores" is important thing to be considered.

Preparing alternative assessment is understood to be an ideal way in facing up the limitation and 'lost learning' towards coronavirus period. Teachers are very 
available with non-desk-paper-test which only conducted in classroom meeting, since it is totally impossible to be held. Multiple assessment is also aligned for teachers to do such the combination of assignments, projects, take-home exams, performance tasks, e-portfolios, students' journals, peer/selfassessment forms, etc. it is important to be understood that this form of assessment should set up the alteration perspective of students, teachers, parents and educational officers that the alternative assessment will put out 'from scores to learning'. The main focus is not merely about scores but it has already come into deeper and wider even longer impacts of learning. In other words, these assessment tools must cover items, tasks and points triggering students' critical thinking, evaluating, criticizing, creating new ideas and innovative products, and activating higher level of students' (soft/hard) skills that are carried out students' uniqueness.

Related those ideal purposive ideas, some relevant points being very important to be highlighted:

\section{No-one-fit-all}

It is being very crucial to know that there are no one assessment will be fit towards all students in all conditions, even under pandemic or non-pandemic situations. Teachers should be considering several ways on assess the students learning process and results.

\section{Be flexible}

In order to support students' ideal ways of learning, teacher forces up on preparing many learning methods and strategies, including the assessment methods and its alternatives.

\section{Be open}

Every single student is unique. Teacher should realize that students are different. They also have different background with the teacher. Listen more towards their uniqueness and learning difficulties is the crucial point. After having balancing understanding between teacher and students, the wider objectives will be achieved, such building and increasing students' selfconfidence.

\section{Be honest}

Believing that teachers themselves is not always 'right' and 'perfect' will lead teachers to be an ideal 'role model' for the students. Understanding that teachers also can make mistakes. Open wider alternative answers towards the alternatives assessments is the main goal of this perspective. Teachers are not the only source of learning and once they make mistake, say sorry to the students is one best way 'be honest'.

\section{3. 'De-testing and De-grading' Reflective Subject}

In one case, a very difficult question raises up in criticizing the de-grading assessment system in pandemic period of time "How do you set up your measurable learning in a class without testing?". It is totally difficult to avoid testing as the only measurable learning. Related to author personal experience, in Speaking class, it is hard to identify that the students get a good score in term of numerical and alphabetical, since the focus is skill and competency of speaking which implement performance task-based. In addition, doing an alternative grading except numerical scoring points is important and applying alternative testing towards projects-based assignment is a choice. Students are forced to finish 'speaking project' as a part of more realistic learning process focuses on creativity and untemplate assignment. In this process, the students' competitiveness being less and the major idea sounds more about real process of learning.

There are some specific alternative assessments are chosen. The description of each project-based assignments are as follows:

\section{Vlog-Based Project}

This project covers some steps: (1) Write down a genre-based text (script making); (2) Make a video of certain topics related to local wisdom (traditional foods and beverages, unique handicrafts and festivals, culinary food-courts, etc.); and (3) Upload it in personal blog and You-tube channel. The standard of uniqueness and creativity assessment is based on the viewers, subscribers and viewer's points stated in comments column.

\section{Narrative Reflection-Sharing Project}

This project covers phases, namely: (1) Re-story a childhood life which gives huge impact on self-future dream; (2) Re-tell the life story through group sharing; and (3) Emphasize the strongest plot of story which gives motivation to own-self and others.

\section{Narrative History Project}

This project covers some steps: (1) Write down a narrative towards historical story of the hometown (script making); (2) Make a video; and (3) Upload it in personal blog and You-tube channel. The standard of uniqueness and creativity assessment is based on the viewers, subscribers and viewer's points stated in comments column.

The main point of de-testing and de-grading focuses on students' choices towards the projects. The score is kept until the end of semester since as teacher are forced 
to submit our report towards students learning process in the form of scores from testing. The author as teacher will only do it once at the end of semester to report score, in order to fulfil the needs of parents and administrators. During the semester, the teacher focuses on enhancing students' competences and skills towards some non-test projects which have deep meaning of creativity and avoid group competition which focus on grading and scores. In other words, teacher will delay the score and give students more chance to develop their speaking skill and capability. Moreover, individual strengths are the main purpose of this non-test project. first, giving appreciation and second, giving orally and written feedback on their wonderful projects will increase their own self-efficacy, self-esteem and competences. By having more experiences, they will easily choose their own 'speaking method' and 'speaking style', in order to reach 'high critical thinking' and 'creativity' on specific topic and text genre of the author's tones.

In addition, teacher provides democracy-based classroom. Democracy, teacher found this word truly in line with the students different learning styles and creativity-based learning in my classroom. Related to speaking class, usually teacher prepare some projects with alternative topics, not only one topic to be discussed. They can choose their own relevant topics so that they are able to come into deeper explanation and giving them much space in enhancing their capability on speaking. Understanding relevant topic towards their daily life will be easier for them to reach more time, ideas and vocabulary to be mastered in speaking. Relevant with teacher (author) research experiences conducted in 2018, and focused on 'local wisdoms' to enhance speaking skill and the research findings showed it increase more than $70 \%$ of their speaking skill. Teacher believes, these various of topics make them feel free to explore their creativity and perspectives towards a word called 'democracy'.

\section{CONCLUSION}

School closure and distance learning affected al classroom routines. Pandemic and coronavirus period change teachers' way of teaching. Online teaching is chosen as the best way on home-studying. Created more doubt of students and parents towards teaching and learning results. Lost learning understood as one of the impacts of distance learning. De-testing and de-grading seem to be a good choice in educational reform point of view. It is to be crucial to do since a lot of unpredictable situations happened in this pandemic. De-testing and degrading can be done through the alternative assessments set up. Project-based assessment is chosen as the alternative choice of assessment as paper-based test can be conducted. Since the focus of this assessment is not only about scores, then it is clearly defined as de-testing and de-grading.

\section{REFERENCES}

[1] Abidah, A., Hidayatullah, H.N., Simamora, R.M., Fehabutar, D., \& Mutakinati, L. (2020). The Impact of Covid-19 to Indonesian Education and Its Relation to the Philosophy of "Merdeka Belajar". Studies in Philosophy of Science and Education (SiPoSE) Vol.1, No.1, April 2020, pp. $38-49$.

[2] Basilaia, G., \& Kvavadze, D. (2020). Transition to Online Education in Schools during a SARS-CoV2 Coronavirus (COVID-19) Pandemic in Georgia. Pedagogical Research, 5, Article No. em0060. https://doi.org/10.29333/pr/7937

[3] Bower, J., \& Thomas, P. (Revised Ed.) (2016). Detesting and degrading schools: Authentic alternatives to accountability and standardization. New York, NY: Peter Lang.

[4] Firdaussi S.E., Lachgar, M., Kabaili, H., Rochdi, A., Goujdami, D., Firdoussi, L.E. (2020). Assessing Distance Learning in Higher Education durig the COVID-19 Pandemic. Hindawi Education Research International Volume 2020, Article ID 8890633, 13 pages https://doi.org/10.1155/2020/8890633

[5] G. Basilaia and D. Kvavadze, "Transition to online education in schools during a SARS-CoV-2 coronavirus (COVID-19) pandemic in Georgia," Pedagogical Research, vol. 5, no. 4, https://www.pedagogicalresearch.com/article/trans ition-to- online-education-in-schools-during-asars-cov-2- coronavirus-covid-19-pandemic-in7937, 2020.

[6] Hast, M. (2020). Higher Education in Times of Covid-19: Giving Online Feedback Implementation Another Look. Canadian Center of Science and Education. doi:10.5539/hes.v11n1p1. https://doi.org/10.5539/hes.v11n1p1

[7] Martini, M., Gazzaniga, V., Bragazzi, N. L., \& Barberis, I. (2019). The Spanish influenza pandemic: A lesson from history 100 years after 1918. Journal of Preventive Medicine and Hygiene, $\quad 60(1)$, E64-E67.

https://doi.org/10.15167/24214248/jpmh2019.60.1.1205

[8] Mustafa, N. (2020). Impact of the 2019-20 Coronavirus Pandemic on Education. International Journal of Health Preferences Research, 112. 
[9] Senel, S., Sene, H.C. (2020). Remote Assessment in Higher Education during Covid-19 Pandemic. Journal of International of Assessment Tools in Education. Vol. 8, No. 2, 181-199. https://doi.org/10.21449/ijate.820140.

[10] Tadesse, S., \& Muluye, W. (2020). The Impact of COVID-19 Pandemic on Education System in Develop- ing Countries: A Review. Open Journal of Social Sciences, 8, 159-170. https://doi.org/10.4236/jss.2020.810011
[11] TUAC Secretariat Briefing (2020). Impact and Implications of the COVID 19-Crisis on Educational Systems and Households (pp. 1-9). The Trade Union Advisory Committee (TUAC) to the OECD.

[12] Zhu, X. D., \& Liu, J. (2020). Education in and after Covid-19: Immediate Responses and LongTerm Visions. Postdigital Science and Education, 1-5. https://doi.org/10.1007/s42438-020-00126-3. 